\title{
Effective Teaching in the Use of Pragmatic Markers for Chinese EFL Learners
}

\author{
Wang Li \\ College of Foreign languages, Nantong University, China
}

Copyright $(\mathcal{C} 2015$ by authors, all rights reserved. Authors agree that this article remains permanently open access under the terms of the Creative Commons Attribution License 4.0 International License

\begin{abstract}
Research on teaching the use of pragmatic markers to L2 learners is a relatively new area and many aspects are still not addressed. It was assumed that negative pragmatic transfer, the limited linguistic input in the course-books that EFL learners are exposed to, and the negative influence of formal instruction were possible driving factors that might cause Chinese EFL learners' problems in using pragmatic markers. Based on the previous research findings, three aspects that might facilitate Chinese EFL learners' acquisition of pragmatic markers were discussed, i.e. noticing of pragmatic markers, instruction on pragmatic markers, and processing of pragmatic markers. Furthermore, teaching practices are also proposed to help teachers teach more effectively the use of pragmatic markers in real conversation.
\end{abstract}

Keywords Pragmatic Markers, L2 Learners, Instruction

\section{Introduction}

Although numerous studies have been done to specify the meanings, functions or classifications of pragmatic markers, no universal agreement has been reached on several issues concerning pragmatic markers. A wide variety of other terms (but not limited to these) are: cue phrases (Knott \& Dale[20]), discourse connectives (Blakemore[4]), discourse operators (Redeker [28]), discourse particles (Schourup, [30]), pragmatic connectives (Van Dijk [36]; Stubbs[34]), pragmatic formatives (Fraser [8]), discourse markers (Fraser[9]), pragmatic markers (González[11]), and pragmatic operators (Ariel[3]), etc. Each term only partially overlaps with the others.

The term "pragmatic marker", suggested by Andersen [2], describes a class of short linguistic elements that usually do not have much lexical meaning but serve significant pragmatic functions in conversation. Andersen [2] believes that the term "pragmatic" denotes the quality of "low degree of lexical specificity" and a "high degree of context-sensitivity". He proposes that pragmatic markers help readers/hearers "see" the communicative aspects that go beyond the propositional meaning of an utterance. They are called pragmatic because they add an inferential trace to the proposition itself, making the interpretation of the discourse easier and narrowing the contextual background.

According to Schourup [31], there are two characteristics of pragmatic markers which are most often mentioned as criteria to identify a pragmatic marker status: connectivity and non-truth conditionality. Connectivity is considered a necessary criterion for pragmatic markers. Pragmatic markers are used to connect the host utterance with its context locally or globally. They function to ensure the right interpretation of the utterance by guiding the hearer in choice of appropriate context, or to help achieve discourse coherence by making the implicit relationship between discourse units explicit. Non-truth conditionality refers to the belief that pragmatic markers do not contribute anything to the truth-conditions of the proposition expressed by an utterance, that is, they do not affect the propositional content of utterances in which they occur. Considering the second characteristic, pragmatic markers can be removed without influencing either the propositional content or the grammatical structure of the utterances they introduce.

However, not until the end of last decade did the research on pragmatic markers begin in China, with He and Ran [14] being two of those contributing to the pioneering work in this issue. Theoretical research on pragmatic markers in China takes different perspectives. Some studies view pragmatic markers as constraints on relevance within relevance-theoretic framework. He and Ran [14] make a tentative study of pragmatic markers focusing on their pragmatic constraints on utterance production and interpretation and conclude that pragmatic markers can reveal the short-circuited information and minimize the hearer's processing efforts. Along the same line are the pragmatic functions of pragmatic markers analyzed by $\mathrm{He}$ and $\mathrm{Mo}$ [13] and $\mathrm{Li}$ [21]. Chen [6] presents a contrastive pragmatic analysis of discourse end markers (e.g. ne, $m a$, and $n a$ ) in Chinese and English conversations by following the relevance-theoretic approach and demonstrates the influence of such markers on utterance proposition. Others 
study pragmatic markers in translation. Ran[26] conducts a contrastive study of pragmatic markers between English and Chinese and points out that while showing some differences, pragmatic markers in both languages perform a common function of pragmatic marking. He thus suggests that in translation of pragmatic markers we should focus on their pragmatic functions in the source text and represent them appropriately in the target text. There are also studies exploring the pragmatic meanings and functions of pragmatic markers. Ran [26] focuses on the pragmatic marker you know and claims that it is found not to contribute to the propositional content of the utterances to which it is attached; rather it is used as an adaptive device helping to manage and maintain the on-going interaction in verbal communication. In context, it serves as a meta-knowledge indicator and its function of calling attention leads to the increase of shared knowledge between the participants. He concludes that such a pragmatic marker appears as a result of adaptation to the context in communication. Ran[26] also studies the pragmatic functions of another pragmatic marker well and claims that it can act as a mitigator of face-threatening acts, a hesitation or delay marker of some speech acts, and an insufficiency marker or repair marker in different contexts. $\mathrm{Li}$ [21] shows that speakers use pragmatic markers not only to organize discourse and attract hearers' attention, but also to express speakers' attitude and maintains discourse coherence.

$\mathrm{Wu}$ and $\mathrm{Yu}[39]$ focus on the pragmatic markers' function of reflecting language users' metapragmatic awareness and explore the relationship between pragmatic markers and metapragmatic awareness as well as five types of metapragmatic information conveyed by pragmatic markers. Their studies focus on analysing the pragmatic meanings and functions of individual pragmatic markers like well and you know as well as pragmatic markers in general. Their research has showed that pragmatic markers work as a linguistic structure that does not exert any effect on the truth-value of the utterance, but expresses attitudinal and procedural meanings. They reflect the adaptation made by language users to contexts; meanwhile, they help language users construct discourse and perform different pragmatic functions to facilitate communication. In this connection, pragmatic markers may be classified into three categories: (1) those that indicate that the present utterance and the previous one are semantically or logically related; (2) those that are mostly hedges and show that the utterance introduced by pragmatic markers has no necessary logical relation with the previous or the following utterance in discourse progressing; and (3) those that signal the introduction of the following utterance without positing its logical connection with the previous one.

Wang [37] showed that Chinese EFL learners generally utilized significantly fewer pragmatic markers and used a narrower range of pragmatic functions than native speakers. The findings on the ranges of pragmatic functions used by Chinese EFL learners in the present study echo the previous findings. Nikula[25], in her study of hedge-like modifiers among Finnish speakers of English, says: "as far as the types of expression used are concerned, the non-native speakers had a narrower range at their disposal even though they used most of the modifiers that ranked highest in native speakers' performance". Hasslegren[12] studies two groups of Norwegian pupils with native speakers in the use of what she called "small words". She finds that even the more fluent pupils fall short of native speakers in the size of the pool of pragmatic markers they draw on. Raupach[27] finds that even after staying abroad and acquiring extended vocabulary, students, as a group, stuck to a very similar and restricted repertoire of organizing formulae. She also finds that a major difference between the natives and more fluent non-natives is the relative lack of variety in the latter group's choice of pragmatic markers, which put them at a disadvantage in terms of creating the correct pragmatic effect.

\section{Background and Context}

As for the limited use of pragmatic markers and narrow range of pragmatic functions by Chinese EFL learners, we assume that two factors may contribute to the poor use: the limited linguistic input in the course-books that EFL learners are exposed to and the negative influence of formal instruction.

Appropriate linguistic input is, of course, an important factor, as recognised by all theories of L2 language acquisition, albeit to differing degrees (Ellis [7]). Although recently, research in pragmatics has begun to leave its mark on English language course-books which have begun to include such spoken aspects in texts, the traces of history are still apparent - appropriate exercises are still lacking in Chinese EFL classroom (Jiang [17]). Related to the lack of appropriate input in the form of course-books is the fact that the interpersonal function of language is often sacrificed in language classes. Many locally produced course-books claiming to represent the details of English usage primarily focus on form rather than on meaning and use. For example, the adverb meaning of well is more frequently emphasized in the course-books, and hence this study showed that Chinese EFL learners employed a large proportion of wells as adverbs, whereas its pragmatic functions in spoken English were ignored.

Instruction seems to have a strong positive role in helping L2 learners acquire and perform L2 pragmatics (Kasper \& Schmidt [19]). In foreign language learning contexts, learning occurs almost exclusively in classrooms where many teachers share the same L1 and cultural background as their students, and where only a limited range of social interactions is provided, e.g., shorter and less complex discourse organizations, minimal openings/closings and fewer discourse and politeness markers (Lörscher[22]). L2 teachers often do not teach pragmalinguistic information because they are not consciously aware of it themselves. Pragmatic competence is the most difficult aspect of language to master in learning a second language 
(Blum-Kulka \& Sheffer[5]).

Moreover, the traditional grammar-centered pedagogic focus has been geared towards the literal or propositional meanings of words rather than their pragmatic use in spoken language. A general neglect of pragmatic markers in the foreign language teaching curriculum seems to be the pedagogic reality (Fung \& Carter[10]). Owing to the common perception that pragmatic markers are signs of indecisiveness or hesitancy and thus are not a commendable feature for language learners, pragmatic markers are often left behind in the formal language classroom (Trillo[35]). This is clearly the case in China since pragmatic markers are generally neglected in teaching materials and in the English curriculum. Teaching guidelines and materials on pragmatic markers are rare. It is likely that the low propositional meanings of pragmatic markers have devalued their pedagogic significance, and thus leading to their low status. Without some form of instruction, many aspects of pragmatic competence do not develop sufficiently (Kasper [19]). Thus, it is certainly a question that requires serious consideration from educators and language policy-makers.

Therefore, in order to improve Chinese learners' speaking competency, the specific pragmatic functions of the pragmatic markers should be taught more explicitly in EFL classrooms and be included in the course-books.

Wang[37] also found that the Chinese EFL learners generally used the function of monitoring marker significantly more frequently than native English speakers, which is mainly caused by the prevalence of you know as a monitoring marker among Chinese EFL learners. The results also revealed that Chinese EFL learners used significantly more well and actually as a face-threatening mitigator. We assume that negative pragmatic transfer is the driving factor that may explain the underlying motive for these phenomena.

The term "transfer" is generally used to refer to the systematic influences of existing knowledge on the acquisition of new knowledge. People usually approach a new problem or situation with an existing mental set: frame of mind involving an existing disposition to think of a problem or a situation in a particular way. Mental sets are largely determined by culture-specific knowledge. Therefore, L2 speakers' communication may be influenced by their different mental sets of L1 and they may mistakenly generalize from pragmatic knowledge of L1 to a L2 setting (Kasper[18]).

Kasper[18] defines pragmatic transfer as "the influence exerted by learners' pragmatic knowledge of languages and cultures other than L2 on their comprehension, production, and acquisition of L2 pragmatic information". When learners project their L1 pragmatic knowledge to L2 language context and such projection result in learners' perception and production of speech behaviors feature same with L2 native forms, then positive transfer occurs; whereas while learners' projection of L1 pragmatic to L2 result in their speech behaviors feature different with L2 native forms, then it is regarded as negative transfer. But the influence of one language upon another may bring about different results: excessive use (or abuse) of one form or function; and under-use (or avoidance) of forms and/or functions.

Kasper[18] holds that pragmatic transfer has manifested itself in two ways or categories, namely pragmalinguistic and sociopragmatic. Pragmalinguistics refers to our linguistic knowledge of language use, and sociopragmatics is related to how our sociological knowledge influences our interaction. A pragmalinguistic transfer is the influence of the learner's knowledge about the illocutionary force or politeness value assigned to particular linguistic form-functions in L1, which, when mapped by learners into the perception and production of a similar situation in L2, sounds different to native speakers. In Kasper's words, it is "the process whereby the illocutionary force or politeness value assigned to a particular linguistic material in L1 influences learners' perception and production of form-function mappings in L2". Chinese EFL learners may come to the acquisition of the pragmatic markers of their L2 predisposed by the basic distinctions of their L1 so that they will search the input language for similar distinctions. If they find such similarities, they will use these as a basis for pragmatic marker use.

A sociopragmatic transfer refers to a process "operative when the social perceptions underlying language users' interpretation and performance of linguistic action in L2 are influenced by their assessment of subjectively equivalent L1 contexts". With regard to socio-pragmatic transfer, the culturally-based principles or maxims that underlie interactants' performance and interpretation of linguistic action should be taken into consideration. These principles or maxims include both culturally-based assessments of the typical characteristics of a given communicative activity (e.g. typical degrees of distance and equality/inequality between participants, people's rights and obligations and so on) and culturally-influenced dynamic assessments of actual communicative events. Chinese cultural and Western culture are sharply distinct from each other and hence the notions of face and self-image are conceptualized differently from one culture to another, depending on the underlying cultural values and beliefs. Chinese culture is characterized by a strong emphasis on the group, which can be traced to both traditional norms that encourage the Chinese "to perfect oneself, family, country, world"(Confucius), to depend on each other for support and protection, and to preserve the extant social order. Jandt [16] observes that for the Chinese, respecting the relationship is achieved through group harmony, avoidance of loss of face to others and oneself, avoidance of saying what one actually thinks when it might hurt others in the group, and a modest presentation of oneself. For instance, one does not say what one actually thinks in order to avoid hurting others in the group. Hence, communication, which is pervasively influenced by Confucianism, will be defined as "an indefinite interpretive process where all parties are searching to develop and maintain a social relationship".

However, these studies only focus on the theoretical 
efforts and do not discuss the possible factors that might facilitate the acquisition of pragmatic markers and do not provide pedagogical practices for Chinese teachers to teach students how to use pragmatic markers in spoken discourse.

\section{Possible Factors That Might Facilitate the Acquisition of Pragmatic Markers}

The previous studies discussed so far have shown that Chinese EFL learners have not succeeded in acquiring the use of pragmatic markers. Compared to native speakers, these learners showed obvious differences in pragmatic marker use. Since the use of pragmatic markers can contribute to naturalness and interactivity of speech, this deficiency in pragmatic marker use results in an unnatural and awkward speech patterns. According to Wilson and Sperber[33], pragmatic markers encode procedural meaning and cannot be brought to consciousness. For this reason it is often difficult to notice, let alone to acquire pragmatic markers. But this is only one explanation for the learners' difficulty in acquiring pragmatic markers. Possible factors contributing to the learners' acquisition of pragmatic markers are discussed from three aspects: noticing of pragmatic markers, instruction on pragmatic markers, and processing of pragmatic markers.

\subsection{Noticing of Pragmatic Markers}

According to Schmidt [29], only when input is noticed can it become intake and effective processing. Therefore, a degree of awareness is important before input can be incorporated into a developing interlanguage system. The acquisition of pragmatic markers by L2 learners is first analyzed according to the six influences upon noticing suggested by Schmidt.

Theoretically speaking, the more frequent a pragmatic marker is in the input stream, the more likely it is to be noticed and then become integrated into the interlanguage system. Thus, it is suggested by the author that, in order to facilitate their acquisition of pragmatic markers, the learners must be exposed more to spoken discourse and be instructed on the use of pragmatic markers. Subsequently, the more a pragmatic marker stands out in the input stream, the more likely that it will be noticed. According to Sperber and Wilson [33], pragmatic markers express procedural information and cannot be brought to consciousness. In other words, pragmatic markers are not perceptively salient because they do not express conceptual meaning. Therefore, there is slim chance for pragmatic markers to be noticed and acquired by the learners.

Although they are not perceptively salient, the learners' awareness of pragmatic markers can be aroused by way of instruction. Instruction can make relevant the less obvious aspects of the input. It channels attention and brings into awareness what otherwise would have been missed. Considering that pragmatic markers are not easily noticed, instruction seems quite necessary in the case of pragmatic marker acquisition. Otherwise, they would often be neglected. What the present oral discourse falls short of is the opportunity to focus on pragmatic markers. So, it is advocated here that formal instruction on pragmatic markers be introduced.

Only when this is done can acquisition of pragmatic markers be more efficient and fruitful. Processing ability concerns the learner's capacity to deal with the range of forms in input. A person's processing ability is limited. When part of the capacity is occupied with one task, less is available for another. So when the learners concentrate more on meaning or forms rather than pragmatic markers, they are less likely to notice pragmatic markers, and thus the acquisition of pragmatic markers is less likely to take place.

In order to make the learners fully aware of pragmatic marker use, tasks should not be too demanding. Other aspects of language should not distract them too much to make sure that enough capacity is available for the processing of pragmatic markers. According to two studies on the acquisition of pragmatic markers by young children, the acquisition of pragmatic markers tends to develop from that of the literal meanings to that of the pragmatic meanings (Andersen[2]). For the learners who have acquired the literal meanings of pragmatic markers, a prediction can be made that noticing and acquiring the pragmatic functions of pragmatic markers will subsequently take place, because it is the "next" thing to be acquired. Finally, according to Schmidt [29], more demanding tasks consume more attention resources for task transaction, thereby leaving less attention available for focus on form. When a learner's limited processing capacity system is overloaded, noticing is less likely to take place. So the design of tasks for formal instruction on pragmatic markers should take task-difficulty into consideration.

In conclusion, the lack of frequent input as well as perceptive salience and instruction may lead to the learners' failure to acquire pragmatic markers. To ensure their acquisition of pragmatic markers, formal instruction should be adopted so that pragmatic markers are frequent and prominent enough to be noticed then acquired. Formal instruction should take processing capacity and the current state of the learners' interlanguage into consideration, as well task difficulty. There are two main principles behind the noticing tasks: on one hand, they encourage learners to compare their expectations of native-speaker English and the reality of native-speaker English, and on the other hand, they encourage learners to compare their words with what native speakers would say.

\subsection{Instruction on Pragmatic Markers}

Trillo[35] proposes a "binary track" that foreign language learners follow in their linguistic development: the formal track and the pragmatic track. The formal track relates to the grammatical and semantic rules that conform to the competent use of a given language; the pragmatic track, on 
the other hand, relates to the social use of language in different contexts and registers.

Native speakers would develop both tracks simultaneously by means of natural language contact, and thus would establish a mutual relationship between both tracks. Non-native learners, however, would develop the formal and the pragmatic tracks through formal instruction because they are not in a target language environment. The difficulty, therefore, is that the pragmatic track, linked to the cognitive, affective, and socio-cultural meanings expressed by language forms, is difficult to implement in educational syllabuses. Furthermore, it is difficult to produce (pseudo)-natural foreign language context that the development of pragmatic competence demands. Consequently, the pragmatic knowledge is often neglected in the curriculum, and thus the use of pragmatic markers becomes fossilized both in the quantity and the diversity of elements used (Trillo[35]). He mentions that there is an urgent need to bring the consistent teaching of pragmatic markers to language instruction, as well as the need to investigate the development of pragmatic markers in speech in order to monitor pragmatic competence and pragmatic fossilization in non-native speakers.

Instruction can be conducted in various ways. It can be directed at cognitive goals, for example, focusing on drawing the learners' attention to the pragmatic markers used by native speakers and allowing them to acquire the pragmatic use of pragmatic markers and thus developing their communicative competence. Instruction can also be directed at metacognitive goals, attempting to train the learners to use effective learning strategies. It is more desirable for the learners to acquire the pragmatic use of pragmatic markers in carefully designed tasks that can produce (pseudo)-natural foreign language context. According to the informationprocessing approach to task-based instruction proposed by Skehan [32], the balance should be kept between communication and form. Therefore the design of the tasks for instruction should balance the chance for a focus on both the form and functions of pragmatic markers in communication to maximize the efficiency of the acquisition process of pragmatic markers. Within given information-processing capacities, the tasks should be less demanding, for less attention will be channelled for task transaction and more attention can become available for a focus on pragmatic markers. In short, through attention-manipulation in formal instruction on pragmatic markers, more attention will be available to focus on pragmatic markers in communication, yielding a more effective acquisition process of pragmatic markers. As a result, the product of such acquisition can facilitate the use of pragmatic markers.

\subsection{Processing of Pragmatic Markers}

According to VanPattern[36], learners process content words in the input before anything else, and for learners to process form that is non-meaningful, they must be able to process information or communicative content that costs little or no resources of attention. Since pragmatic makers do not express conceptual meaning, they cannot be processed before content words. Additionally, there is a lack of exposure to the use of pragmatic markers in the input material, as can be seen from the data analysis presented earlier in the present study. So it is even less likely for the learners to process pragmatic markers. Meanwhile pragmatic markers cannot be seen as non-meaningful, for they do express procedural meaning. Only when the learners are able to process the content without extra attention resources is it possible for pragmatic markers to be processed, due to the learners' limited processing capacity.

The processing approach asserts that it is useful to train language learners in effective processing and to make them more aware of the relevant cues in the language input so that form-meaning links are more likely to be addressed (Skehan[32]). According to VanPattern's model of processing and acquisition, instruction on the input processing of pragmatic markers should be focused on the input-to-intake stage; where the input is processed to make the form of pragmatic markers more relevant in order to encourage learners to deliberately attempt to focus on them. Such instruction can maximize the efficiency of this stage in the processing of pragmatic markers so that the process of acquisition can work more effectively.

\section{Effective Teaching in the Use of Pragmatic Markers}

\subsection{Consciousness Raising and Explicit Teaching}

As revealed in this exploration, pragmatic markers perform a wide range of pragmatic functions that are crucial for L2 speakers in interactions. It is necessary to approach the teaching of foreign languages from a pragmatic point of view. Therefore, the multifunctional nature of pragmatic markers should be communicated to syllabus designers, material developers, classroom teachers and L2 learners in China to raise the consciousness of pragmatic markers. Such consciousness will exert a positive effect on spoken English teaching and learning. It will equip the syllabus designers with principles to determine the learning goals of the variety of pragmatic functions and include activities in which the students can participate actively, as well as communicative, cooperative tasks that allow the use of pragmatic markers. If the materials developers are aware of the importance of the pragmatic markers, they will include pragmatic components in their textbooks in an explicit way. The raised consciousness of pragmatic markers may be an advantageous beginning for the learners to acquire the pragmatic functions, especially the pragmatic functions which have been underused in the sequential and rhetorical structures.

While consciousness-raising activities to pragmatic markers are doubtless essential for improving the pragmatic marker use of L2 learners, explicit teaching of pragmatic 
markers also seems highly desirable. Explicit teaching will strengthen L2 learners' pragmatic competence in spoken language by incorporating the use of pragmatic markers into the language curriculum to improve their use of pragmatic markers, to enhance natural and fluent conversation, to help avoid misunderstanding in communication, and essentially, to provide learners with a sense of security in L2. Over the past two decades, researchers have established that a foreign language learner's development of various aspects of pragmatic competence may be facilitated by the instruction of pragmatic routines and strategies in the foreign language classroom (Kasper[19]). When such instruction is explicit, it appears to be particularly beneficial since it enables learners to develop an awareness and understanding of the differences between L1 and L2 pragmatic preferences, and thereby "counteract negative L1 transfer through "noticing" (Schmidt[29]) and through making attempts to use alternative, more L2 norm-oriented expressions (House[15]). Since suggestions for the explicit teaching of pragmatic markers are rare to date, the following section is devoted to the question of how pragmatic markers should be taught. The suggestions are largely based on the research findings of the present study and intended for pragmatic markers investigated, for Chinese EFL learners, and for general language courses.

\subsection{The I-I-I-I Teaching Methodology}

In regards to the teachability of pragmatic markers, Fung \& Carter [10] maintains that there is some evidence in second language learning to support a sequential input of naturalistic spoken discourse features, initially for comprehension followed by production. Similarly, McCarthy [23] supports the idea that production should be delayed until suitable natural opportunities arise. J. Willis and D. Willis [38] suggest that a teaching process can start with activities to bring about an increased awareness of and sensitivity to the target language where learners are encouraged to notice particular features of the language, to draw conclusions from what they notice and to organize their view of language in the light of the conclusions they have drawn through analytical strategies like highlighting, questioning, explaining, identifying, comparing with mother tongue, etc.. The language awareness-based I-I-I (illustration-induction-interaction) paradigm proposed by McCarthy and Carter[19], mediates through activities like language observation, problem-solving, and cross-language comparisons, can be more helpful in bringing out the meaning and usage of various pragmatic markers in a natural manner. However, the I-I-I approach may need to be revised to make students aware of the use of pragmatic markers in spoken language and of a range of functions that these markers perform.

Based on McCarthy and Carter's [23] model, we propose the I-I-I-I methodology, standing for "Illustration-Interaction-Induction-Internalisation", to teach pragmatic markers in EFL classroom. "Illustration" refers to the presentation of authentic data of pragmatic marker use in the relevant context. "Interaction" suggests introducing learners to discourse-sensitive activities which are designed to raise the awareness of the interactive properties of pragmatic marker use through observation and class discussion. "Induction" is to encourage learners to draw conclusions about the pragmatic functions of a given pragmatic marker and the capacity of noticing the differences. "Internalisation" refers to the capacity to use markers such as well, you know, I mean, and actually appropriately. Since pragmatic markers interact with the discourse environment and convey meaning which cannot be straightforwardly brought to consciousness, this is an appropriate strategy to provide interpretive clues to the interlocutor as to how the upcoming discourse should be interpreted. It is also suggested that in order for teachers to fully apply the research-based I-I-I-I teaching methodology in an EFL classroom, the following points should be duly noted.

Teachers should make it clear to students that incorrect or inappropriate use of pragmatic markers can lead to misunderstandings and difficulties in establishing a coherent interpretation of discourse as well as limiting the extent to which interpersonal relations can be effectively expressed. Teachers should also clarify various pragmatic functions of pragmatic markers to the students, especially the pragmatic functions in the rhetorical structure and the sequential structure, which have been underused significantly by Chinese EFL learners. It is expected that the findings of this research will make the teaching and practice of pragmatic markers become an essential part in the Chinese EFL classroom.

One of the most effective ways to teach the use of pragmatic markers is to ask students to infer the correct marker from the context by means of some exercises specially designed to challenge students. Teachers can have students observe how pragmatic functions are conveyed within the context of the dialogue by means of these pragmatic markers. Students compare the original with the adapted dialogues, or even with other authentic samples. With teachers' assistance, students discuss the strategies they recognize, and the functions in English culture, in comparison with their own culture. In this way, teachers can help expand students' pragmatic competence by raising their awareness of what is and is not appropriate in given contexts (Kasper [18]).

Let us take well as an example. First, teachers should call the students' attention to the use of well as pragmatic markers while students are reading or listening to conversations or lectures. Once students start paying attention, they will be surprised how often well is used as pragmatic markers in both formal and informal situations. American soap operas such as "Friends", popular in the first decade of this millennium, are filled with pragmatic markers. We can play a video clip from a TV series like this to your class and get students to notice and infer the use of well as pragmatic markers in speech. 
Teachers can call students' attention to how the characters in the soap opreas open a topic, move on to another point, to close a conversation, to raise an important issue, to bring the conversation back to a former point, to add onto a point just raised, and to conclude an argument by using well. Then students can discuss how effective the characters are in the use of pragmatic markers and what might be more effective.

After students have had some practice recognizing markers in spoken discourse, teachers can have them match cards with the pragmatic markers on one card and its definition/function on other. In this way, students may clarify and make explicit what they have implicitly learned through exposure.

The next step would be to take a couple of paragraphs of written discourse in which teachers have deliberately deleted the use of well as markers, and see how well students can fill in the deletions. Teachers may have them compare their answers with each other and then go over the paragraphs with a class as a whole. Teachers can also give students the basic situation and perhaps topic of conversation and have them write a conversation between two friends in the cafeteria, or a husband and wife at dinner, and so forth. Teachers should tell them to include at least three markers. Once their dialogues have been written and checked by teachers, teachers may have volunteers perform and have the class comment on the use of well until students fully internalize the use of well as markers.

\section{Conclusions}

Based on the previous research findings, this study discussed three possible factors that might facilitate Chinese EFL learners' acquisition of pragmatic markers: noticing of pragmatic markers, instruction on pragmatic markers, and processing of pragmatic markers. Furthermore, teaching practices are also proposed to help teachers how to teach student the use of pragmatic markers in real conversation. Research on teaching the use of pragmatic markers to L2 learners is a relatively new area and many aspects are still not addressed. It was assumed that negative pragmatic transfer, the limited linguistic input in the course-books that EFL learners are exposed to, and the negative influence of formal instruction were possible driving factors that might cause Chinese EFL learners' problems in using pragmatic markers.

\section{Acknowledgements}

The paper derived from a research project, entitled "An investigation into the acquisition of Chinese discourse markers by learners from different language backgrounds" (13YJC740096), sponsored by the Educational Council of the Chinese government in the 2013-2016 academic year.

\section{REFERENCES}

[1] Andersen, G. (Ed.) (1998). The pragmatic marker like from a relevance-theoretic perspective. In A. Jucker, \& Y. Ziv (Eds.), Discourse markers: Descriptions and theory (pp. 147-170). Amsterdam: John Benjamins.

[2] Andersen, G. (2001). Pragmatic markers and sociolinguistic variation: A relevance-theoretic approach to the language of adolescents. Amsterdam and Philadelphia: John Benjamins.

[3] Ariel, M. (1994). Pragmatic operators. In R.E. Asher (Ed.), Encyclopedia of languages and linguistics (Vol. 6, pp. 3250-3253). Oxford : Pergamon Press.

[4] Blakemore, D. (1992). Understanding utterances: An introduction to pragmatics. Oxford: Blackwell.

[5] Blum-Kulka, S., \& Sheffer, H., (1993) The metapragmatic discourse of American-Israel families at dinner. In G. Kasper, \& S. Blum-Kulka (Eds.), Interlanguage pragmatics (pp.196-223). Oxford: Oxford University Press.

[6] Chen,Xinren[陈新仁],2002, 《话语联系语与英语议论文写 作:调查分析》.外语教学与研究(5): 350-354.

[7] Ellis, R. (1994). The study of second language acquisition. London: Oxford University Press.

[8] Fraser, B. (1987). Pragmatic formatives. In J. Verschueren, \& M. Bertucelli-Papi (Eds.), The pragmatic perspectives (pp. 179-194). Amsterdam and Philadelphia: John Benjamins.

[9] Fraser, B. (1988). Types of English discourse markers. Acta Linguistica Hungarica, 38,19-33.

[10] Fung, L., \& Carter, R. (2006). Cantonese e-discourse: A new hybrid variety of English. Multilingua, 26(1), 35-66. González, M. (2004). Pragmatic markers in oral narrative: The case of English and Catalan. Amsterdam and New York: John Benjamins.

[11] González, M. (2004). Pragmatic markers in oral narrative: The case of English and Catalan. Amsterdam and New York: John Benjamins.

[12] Hasselgren, A. (2002). Learner corpora and language testing: Small words as markers of learner fluency. In S. Granger (ed), Computer learner corpora, second language acquisition and foreign language teaching (pp. 143-173). Philadelphia: John Benjamins.

[13] He, Ziran \& Mo, Aiping[何自然, 莫爱屏],2002, 《话语标记 语与语用照应》.广东外语外贸大学学报(1).

[14] He, Ziran \& Ran, Yongping. (1999), Pragmatic constraints of discourse connectors. FLTRP(3)

[15] House, J. (1996). Developing pragmatic fluency in English as a foreign language: Routines and metapragmatic awareness. Studies in Second Language Acquisition, 18(2), 225-252.

[16] Jandt, F. E. (1998). Intercultural communication: An introduction (2nd ed.). Thous and Oaks, Calif.: Sage Publications.

[17] Jiang, M.H. (1994). Deutsche Modalpartikeln als Lehr- und Lernproblem im Fach Deutsch als Fremdsprache für Ausländer mit didaktischen. Überlegungen. Frankfurt a.M., etc.: Lang.

[18] Kasper, G. (1992). Pragmatic transfer. Second Language Research, 8(3), 203-231. 
[19] Kasper, G. and Schmidt, R. (1996). Developmental issues in interlanguage pragmatics. Studies in Second Language Acquisition 18(2), 149-169.

[20] Knott A., \& Dale, R. (1994). Using linguistic phenomena to motivate coherence relations. Discourse Processes, 18(1), 35-62. Ma, Xiao[马萧], 2003, 《话语标记语的语用功能与翻 译》中国翻译 (5): 36-39

[21] Li, Yongzhong[李勇忠], 2003, 《信息短路下的话语标记》. 外语学刊 (3): 21-25.

[22] Lörscher, W. (1986). Conversational structures in the foreign language classroom. In G. Kasper (Ed.), Learning, teaching, and communication in the foreign language classroom (pp.11-22). Aarhus: Aarhus University Press.

[23] McCarthy, M. J. (1998). Spoken language and applied linguistics. Cambridge: Cambridge University Press.

[24] McCarthy, M. J., \& Carter, R.A. (1995). Spoken grammar: What is it and how can we teach it? English Language Teaching Journal, 49(3), 207-218.

[25] Nikula, T. (1996). Pragmatic force modifiers: A study in interlanguage pragmatics. Jyväskylä: University of Jyväskylä Press.

[26] Ran Yongping[由永平], 2002, 《语用标记语 you know 的语 用增量辨析》. 解放军外国语学院学报 (4)

[27] Raupach, M. (1980). Temporal variables in first and second language speech production. In H.W. Dechert, \& M. Raupach, (Eds.), Temporal variables in speech (pp.271-285). The Hague: Mouton.

[28] Redeker, G. (1990). Ideational and pragmatic markers of discourse structure. Journal of Pragmatics, 14(3), 367-381.
[29] Schmidt, R. (1990). The role of consciousness in second language learning. Applied Linguistics, 11(2), 120-158.

[30] Schourop, L. (1985). Common discourse particles in English conversation: Like, well, y'know. New York and London: Garland.

[31] Schourup, L. (1999). Discourse marker. Lingua, 107(3), 227-265

[32] Skehan, P. (1998). A cognitive approach to language learning. Oxford: Oxford University Press.

[33] Sperber, D., \& Wilson, D. (1995). Relevance: Communication and cognition. Oxford: Blackwell. (Original work published 1986)

[34] Stubbs, M. (1983). Discourse analysis: The sociolinguistic analysis of natural Language. Oxford: Basil Blackwell.

[35] Trillo, J.R. (2002). The pragmatic fossilization of discourse markers in non-native speakers of English. Journal of Pragmatics, 34(6), 769-784.

[36] VanPattern, B. (1996). Input processing and grammar instruction: Theory and research. Norwood, NJ: Ablex.

[37] Wang, Li [王丽], 2009, An investigation into the acquisition of pragmatic markers in Chinese EFL learners. Unpublished PhD Dissertation. Shanghai Jiaotong University.

[38] Willis, J., \& Willis, D. (1996). Consciousness-raising activities in the language classroom. In J. Willis, \& D. Willis (Eds.), Challenge and change in language teaching (pp. 63-76). Oxford: Heinemann.

[39] Wu, Yaxin[吴亚欣]\& Yu, Guodong[于国栋], 2003, 《话语标 记语的元语用分析》.外语教学(4):16-19. 